\section{A) Check for updates}

Cite this: Analyst, 2020, 145, 7956

\title{
Explosives detection by swabbing for improvised explosive devices
}

\author{
James M. E. Glackin, ${ }^{a}$ Ross N. Gillanders, (D) *a Frans Eriksson, ${ }^{\mathrm{b}}$ Marcus Fjällgren, \\ Joachim Engblom, ${ }^{\mathrm{b}}$ Salam Mohammed, ${ }^{\mathrm{b}}$ Ifor D. W. Samuel (D) a and \\ Graham A. Turnbull (iD *a
}

\begin{abstract}
Swabs taken from the surface of a suspicious object are a standard method of identifying a concealed explosive device in security-conscious locations like airports. In this paper we demonstrate a sensitive method to collect and detect trace explosive residues from improvised explosive devices using swabs and an optical sensor element. Swabs coated with a commercial fluoropolymer are used to collect material and are subsequently heated to thermally desorb the explosives, causing the quenching of light emission from a thin film luminescent sensor. We report the sorption and desorption characteristics of swabs loaded with 2,4-DNT tested with Super Yellow fluorescent sensors in a laboratory setting, with detection that is up to three orders of magnitude more sensitive than standard colorimetric tests. The method was then applied in field tests with raw military-grade explosives TNT, PETN and RDX, on various objects containing the explosives, and post-blast craters. We show for the first time results using organic semiconductors to detect sub-milligram amounts of explosive sorbed onto a substrate from real explosives in the field, giving a promising new approach for IED detection.
\end{abstract}

Received 1st July 2020,

Accepted 4th October 2020

DOI: 10.1039/d0an01312a

rsc.li/analyst sives sensing have been developed in recent years for direct detection in the vapour or aqueous phase, including electrochemical, ${ }^{3}$ Surface-enhanced Raman spectroscopy, ${ }^{4}$ Surface Plasmon Resonance, ${ }^{5,6}$ and colourimetric tests. Wet chemical tests can be used as a preliminary method of identifying the presence and type of explosive such as the alcoholic potassium hydroxide and Griess tests. ${ }^{7}$ These tests place a drop of the test solution on the swab and the presence of explosive is indicated by a colour change and relies on the user's judgement. A new method for fast, efficient analysis of swabs would be useful in the screening and detection of explosives.

In recent years organic semiconductor explosive vapour sensors have been shown to be highly sensitive to a range of nitroaromatic explosives. ${ }^{8-16}$ Organic semiconductors are flexible, solution-processed materials often used in consumer display electronics like OLED televisions and smartphones. These materials, such as Merck Super Yellow shown in Fig. 1a, are highly conjugated polymers which emit strong luminescence when photoexcited by a laser or LED. However when an electron-deficient nitroaromatic molecule, such as TNT, is absorbed into the electron-rich polymer, excitons generated on the polymer chain can be quenched by an electron transfer process and the luminescence decreases. This light quenching can then be monitored by a photodiode or spectrometer to detect the presence of explosives. Several compact sensor platforms have been developed ${ }^{8,13,16,17}$ (including the commercial FIDO system from FLIR) which can achieve high sensitivity to 
(a)

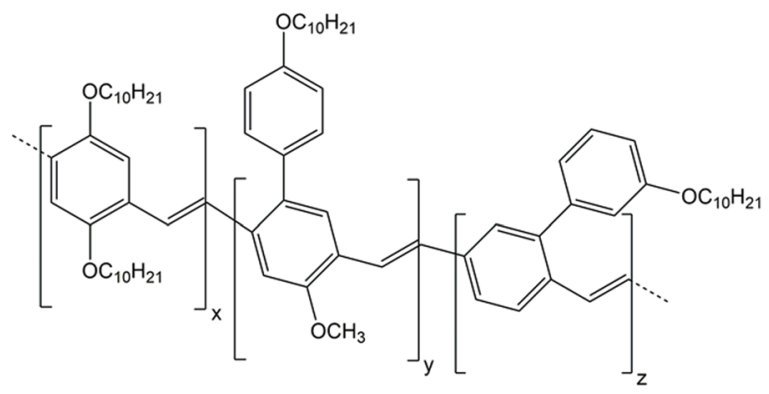

(b)

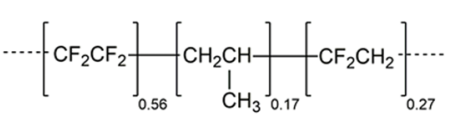

(c) (i)

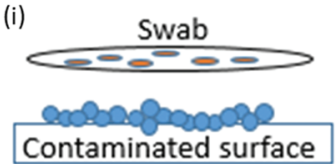

(ii)

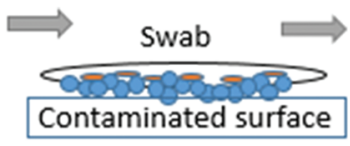

(iii)

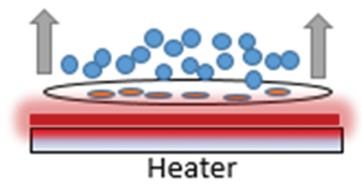

Fig. 1 (a) Chemical structure of Merck Super Yellow. (b) Chemical structure of Aflas. (c) Schematic concept of swabbing with the preconcentrator swabs. (i) The swab is brought to a contaminated surface. (ii) The swab is drawn across the contaminated surface, allowing contaminants to adsorb to the swab. (iii) Heating the swab desorbs the contaminant vapours for subsequent detection by fluorescent polymer film.

trace explosives. However, detecting the required sub-nanogram levels of explosive in the field is extremely challenging ${ }^{18}$ since environmental factors can disperse, degrade or rinse explosive traces from surfaces.

A method to preconcentrate, or sorb, the target molecules can help if only trace amounts are available in the field. An inexpensive fluoropolymer of $\sim 56 \%$ tetrafluoroethylene, $\sim 27 \%$ vinylidene fluoride and $17 \%$ propylene, with the trade name Aflas (Fig. 1b), has recently been shown to passively sorb and thermally desorb explosives on test minefields,${ }^{19}$ and has also shown good sorption capabilities for Volatile Organic Compounds (VOCs). ${ }^{20}$ Polymers of similar structure have been used in the past for explosives concentration, ${ }^{21-23}$ as have graphite sheets ${ }^{24}$ and 3D-printed devices, ${ }^{25}$ though Aflas is an inexpensive, easily-processed, commercially-available solution for the type of large-batch processing required for humanitarian and security-based applications. In a previous minefield-based study with Aflas, air was sampled from a bee colony free-flying over contaminated land, and Aflas-coated papers were inserted into the colony entrance to accumulate explosive molecules from the honeybee bodies. ${ }^{19}$ In the scenario outlined in this work, the same preconcentrators can potentially be deployed for IED detection by physical wiping of the contaminated surface.

The method for swabbing with a preconcentrator-spotted filter paper prior to thermal desorption is shown in Fig. 1c i-1c iii.

In this work we show that a simple swab configuration can be made to sample TNT, PETN and RDX from the raw materials, from a variety of surfaces in a realistic IED package, and from blast craters after detonating the devices, and that the explosive traces on these swabs can be detected by organic semiconductor thin films. We compare the limits of detection (LoD) of trace explosives on a swab using fluorescence quenching and a standard colour change approach using the alcoholic potassium hydroxide method. We find that the fluorescence quenching method has potential to reduce the LoD by up to 3 orders of magnitude.

\section{Method and materials}

\subsection{Swab and polymer sensor preparation}

Swabs were prepared by first dissolving Aflas (AGC Chemicals Europe Ltd) in tetrahydrofuran at a concentration of $155 \mathrm{mg} \mathrm{ml}^{-1}$. Approximately $10 \mu \mathrm{l}$ of the viscous solution was then drop-cast using a micropipette into a $3 \times 3$ grid pattern onto standard $4.5 \mathrm{~cm}$ diameter Whatman filter papers and left to dry. Plain uncoated filter papers were used as control samples, since paper is a commonly used swabbing material due to its fibrous structure. ${ }^{26}$

Sensor films were based on the polymer Merck Super Yellow, which is a commercially-available conjugated polymer that has been shown recently to be an effective sensor of explosives including 2,4-DNT and TNT. ${ }^{19,27,28}$ Super Yellow was dissolved in toluene at a concentration of $6.5 \mathrm{mg} \mathrm{ml}^{-1}$. Glass slides were cleaned by ultrasonication in toluene, acetone and propan-2-ol, and then dried and plasma ashed in a $100 \%$ oxygen plasma (Plasma Technology MiniFlecto) at a pressure of 0.2 mbar. To fabricate a sensor, $40 \mu$ of the Super Yellow solution was deposited on a glass slide and spin-coated at $2000 \mathrm{rpm}$ for 60 seconds to give a film in the region of $100 \mathrm{~nm}$ thickness, and allowed to dry. Samples were stored in the dark in a nitrogen glove-box environment with $0 \%$ humidity and $<10 \mathrm{ppm}$ oxygen when not in use to avoid any degradation of the films. The photophysics and optical characterisation have been described in previous studies ${ }^{13,19,28}$ but briefly, the excitation wavelength of Super Yellow is $440 \mathrm{~nm}$, the peak emis- 
sion wavelength $590 \mathrm{~nm}$, and the photoluminescence quantum yield (PLQY) is $40 \%$ in a film in ambient conditions.

\subsection{Sensing efficiency of Super Yellow to TNT, PETN and RDX}

To assess the typical sensing response of Super Yellow to vapours of TNT, PETN and RDX, three sensor films per analyte were fabricated as described above, and their fluorescence monitored while being exposed to a flow of each vapour. An in-house built nitrogen-carrying manifold branching into separate channels containing $1 \mathrm{~g}$ of each explosive per channel was used to expose the sensor films to near-saturated-vapour pressure of the explosives $^{29}$ ( $\sim 9 \mathrm{ppb}$ for TNT, $\sim 10 \mathrm{ppt}$ for PETN, and $\sim 5$ ppt for RDX). Clean nitrogen was flowed through the chamber between sensing measurements to avoid contamination.

Super Yellow films were exposed to clean nitrogen for $30 \mathrm{~s}$, then exposed to analyte vapour for $195 \mathrm{~s}$, and then again clean nitrogen for $75 \mathrm{~s}$ while being excited by a $405 \mathrm{~nm} \mathrm{CW}$ diode laser (Photonic Solutions). The light emission from the sensors was recorded by an Andor CCD spectrometer cooled to $-40{ }^{\circ} \mathrm{C}$ recording a spectrum every three seconds. The spectra were then integrated for each measurement using a Python script. The sensing efficiency, $\phi$, after the full $300 \mathrm{~s}$ measurement is defined as

$$
\varphi=\frac{\mathrm{PL}_{0 \mathrm{~s}}-\mathrm{PL}_{300 \mathrm{~s}}}{\mathrm{PL}_{0 \mathrm{~s}}},
$$

where $\mathrm{PL}_{0} \mathrm{~s}$ is the unquenched fluorescence at the beginning of the experiment $(t=0 \mathrm{~s})$, and $\mathrm{PL}_{300 \mathrm{~s}}$ is the total photoluminescence of the sensor at $t=300 \mathrm{~s}$ relative to the fluorescence before exposure to the analyte vapour.

\subsection{Swab test experimental set-up}

Sensors were next fabricated to test the swabs for the presence of explosives under similar conditions as those for the vapour experiments. In this case the swab was placed in the sensing chamber in contrast with a ceramic DC heating element (RS Components), as shown in Fig. 2. A k-type thermocouple (RS Components) was used to measure the temperature, which was controlled by an in-house built PID controller and display. Clean nitrogen was flowed through the chamber for 2 min and then the chamber was sealed. The excitation laser and spectrometer were used to record the fluorescence of Super Yellow films as described in section 2.2. After the first $30 \mathrm{~s}$ of recording spectra the heating element was switched on until the swab reached a temperature of $100{ }^{\circ} \mathrm{C}$. The typical heating time of the swabs was $60 \mathrm{~s}$. The heating element desorbed molecules of the explosives from the surface of the swab; these molecules interacted with the Super Yellow film and the resulting decrease in luminescence was monitored.

\subsection{Thermal desorption limit of detection}

To ascertain the minimum mass of explosive that can be detected from thermal desorption, polyester canvas samples were dosed with known small amounts of the model explosive material 2,4-DNT (Sigma Aldrich). A stock solution was created by dissolving 2,4-DNT in acetonitrile which was diluted stepwise to create dosing solutions which were used to deposit 5 $\mathrm{ng}, 50 \mathrm{ng}$ and $500 \mathrm{ng}$ of DNT onto $2.5 \mathrm{~cm} \times 2.5 \mathrm{~cm}$ polyester canvas substrates. The solutions were deposited onto the canvas and left to dry in an extracted fume hood. The swabs and sensors films were then placed in the setup shown in Fig. 2. The chamber was flooded with nitrogen for $2 \mathrm{~min}$ and then sealed prior to heating the swab and measuring the subsequent decrease in luminescence due to quenching. The chamber was then flushed with nitrogen for a further 2 minutes to cool down the heating element before removing the swab and the sample. Reference measurements were taken by turning on the heating element for the same length of time and performing a measurement without a swab.

The LoD of the standard colour change approach using the alcoholic potassium hydroxide method was also measured, to compare with that for fluorescence quenching. Known amounts of 2,4-DNT were deposited onto pieces of polyester canvas and then tested with an alcoholic potassium hydroxide solution. First, 2,4-DNT was dissolved in acetonitrile and concentrations were prepared by serial dilution. These solutions were deposited onto pieces of polyester canvas and left to dry to leave behind a known mass of material of $500 \mu \mathrm{g}, 50 \mu \mathrm{g}$, $5 \mu \mathrm{g}, 500 \mathrm{ng}$, and $50 \mathrm{ng}$ on the substrate surface. The test solution was prepared by dissolving potassium hydroxide in ethanol absolute at a concentration of $1 \mathrm{~g} \mathrm{ml}^{-1}$. 1-2 drops of the potassium hydroxide solution were deposited onto each canvas sample and any colour change noted and photographed using a standard smartphone CMOS camera.

\subsection{Explosives swabbing in the field using typical IED models}

Swabs were tested in both dry and wet configurations to investigate whether dissolving the explosives prior to wiping the surface would better adsorb explosives. In the wet configuration, acetone was used to wet the swab surface. Although acetone may not be the best solvent for each explosive, ${ }^{30-32}$ it is readily available in a field setting from, for instance, local supermarkets or pharmacies, and so is a practical choice of solvent for real-world methodology. The saturation concentration of each explosive in acetone is $0.54,0.08$, and $0.25 \mathrm{~g}$ $\mathrm{ml}^{-1}$ for TNT, RDX and PETN respectively.

IED packages were prepared indoors at the test facility of SWEDEC in a national military explosives laboratory by specially trained personnel. The three explosives were handled under separate extracted fume hoods to avoid cross contamination. TNT granules were poured into a paper container in one, a block of RDX previously removed from an artillery shell was held in a jar in the other, and in the third a piece of PETN was formed into a cylinder wrapped in wax paper with a detonation cord. The raw materials were swabbed with both Aflascoated and non-coated filter papers, with both in dry and wet configurations. The swabs were stored in glass vials and sealed with Parafilm prior to sensor measurement.

Typical IED packages were prepared with TNT, RDX and PETN by personnel of SWEDEC on-site. The explosive materials were handled while wearing latex gloves; the gloves 


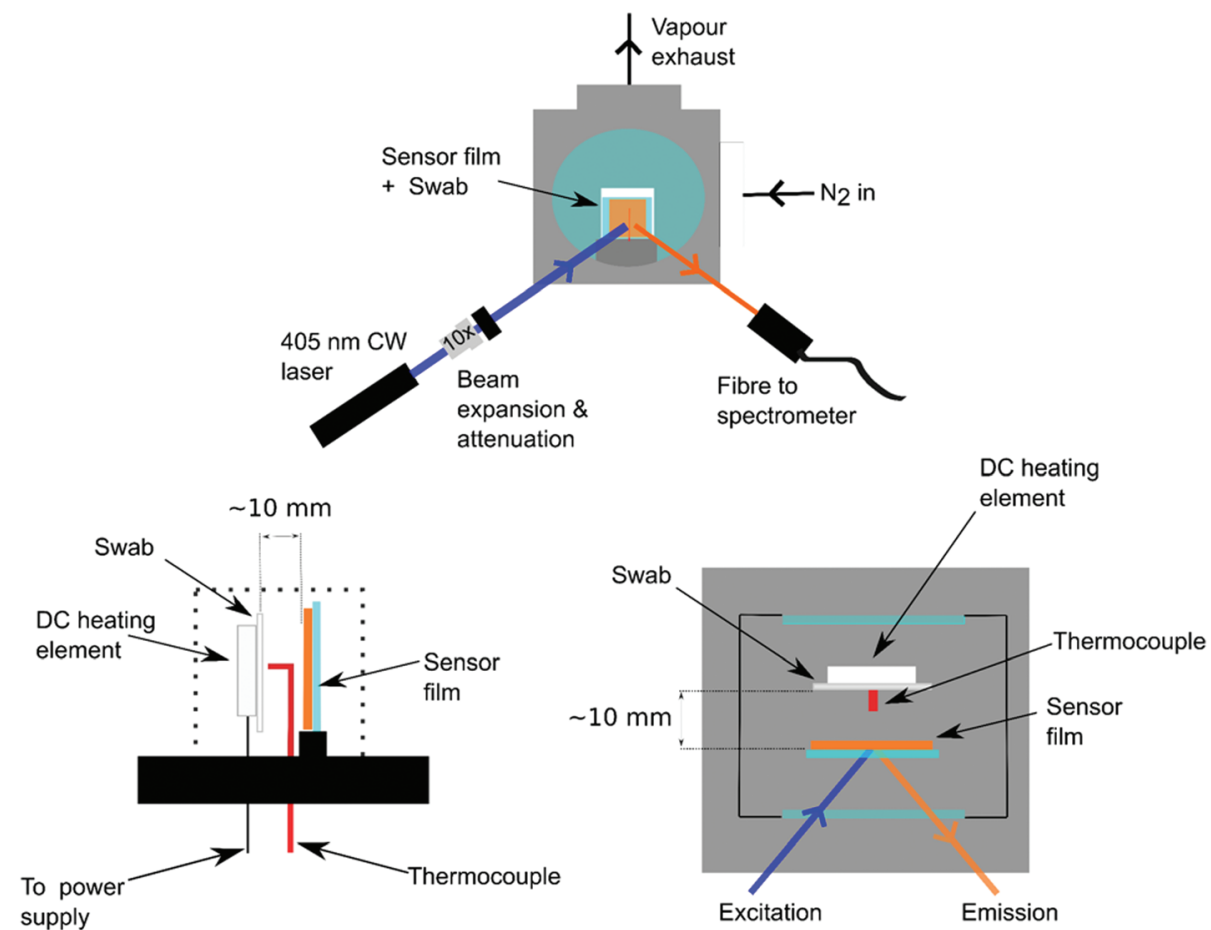

Fig. 2 Experimental set-up for thermally desorbing explosives from a swab and subsequent optical detection. (a) Front-view of the sensor chamber with excitation laser source and spectrometer fibre optic; (b) side-view of sensor chamber; (c) top-view of sensor chamber.

were then used to touch, respectively, the handles and body of a canvas tote bag, a cardboard box, and a nylon sports bag as pictured in Fig. 3 to spread the contaminants on the package in a typical fashion. Swabs were rubbed along the handles and surfaces of the IEDs then immediately sealed.

Finally, the prepared IED packages were taken outdoors and prepared for detonation. The weather was around freezing and dry, with minimal snow coverage. The devices were detonated in a pit in sequence, and a further set of swabs taken from the ground around the blast crater within a radius of $1 \mathrm{~m}$.

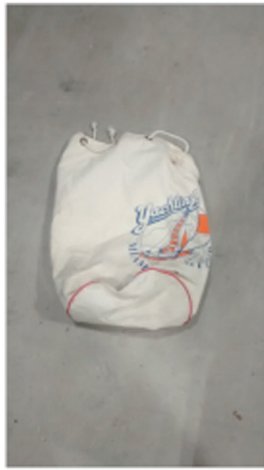

(a)

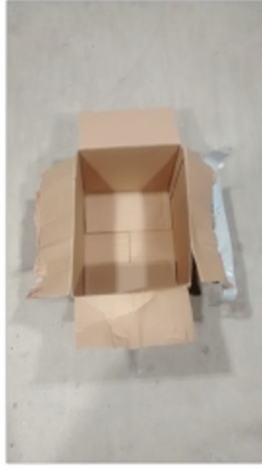

(b)

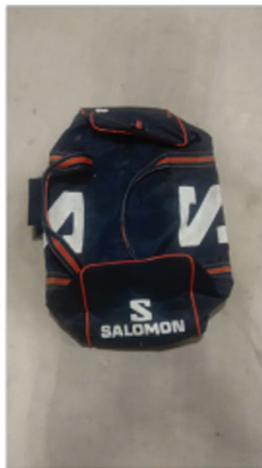

(c)
Fig. 3 Materials used to create the IEDs. (a) Canvas tote bag used to make the TNT-based device, (b) cardboard box used for the RDX-based device and (c) nylon sports bag used to create the PETN-based device.

\section{Results}

\subsection{Sensing efficiency of Super Yellow to explosives at} saturated vapour pressure and pre-loaded swabs

Fig. 4 shows the average response of Super Yellow sensors to vapours of the explosives tested in this study. It can be seen that Super Yellow was quenched by $27 \%$ by TNT, $20 \%$ by RDX, and $26 \%$ by PETN, all at near-saturated vapour pressure using

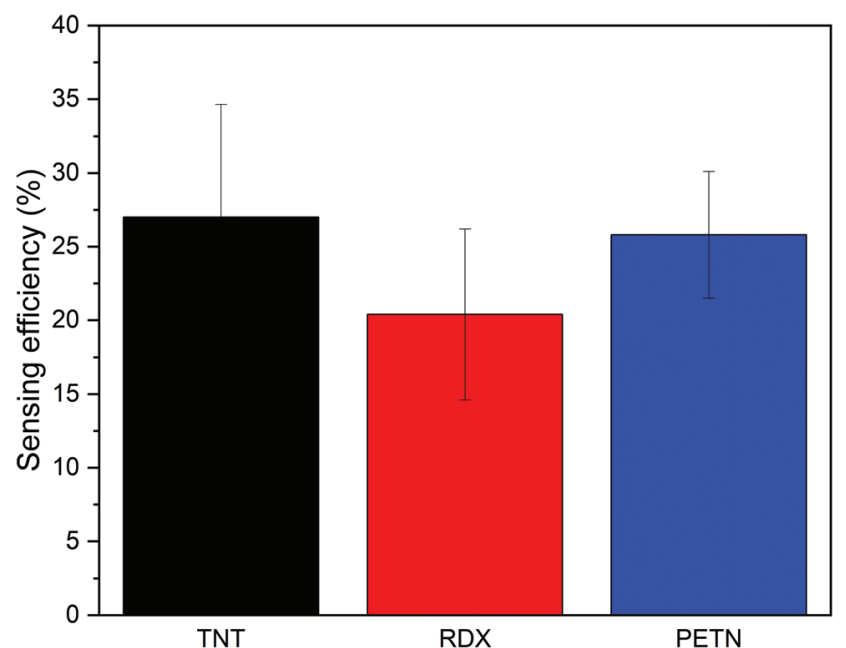

Fig. 4 Average sensing efficiency $(n=3)$ of Super Yellow sensors exposed to saturated vapour pressure of TNT (black bar), RDX (red bar) and PETN (blue bar). 


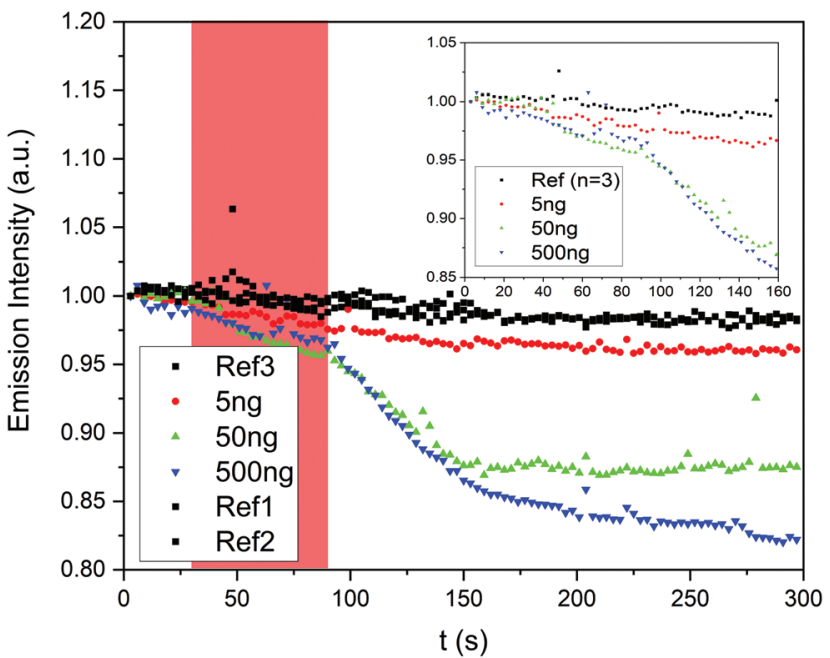

Fig. 5 Response of sensors to swabs with no loading of explosives (black circles, $n=3$ ), loaded with $5 \mathrm{ng}$ of 2,4-DNT (red circles), $50 \mathrm{ng}$ of 2,4-DNT (green "up" triangles) and $500 \mathrm{ng}$ (blue "down" triangles) of 2,4-DNT. The red shaded area indicates when the swab is heated. Inset shows a detail of $0-160$ seconds to highlight the change in intensity between the average of three control samples and the loaded samples.

the set-up described in section 2.2. Fig. 5 shows the change in fluorescence intensity following heating of the swabs predosed with 5-500 ng 2,4-DNT. These are found to give a significant quenching effect of the sensor films, with the $500 \mathrm{ng}$ sample of DNT causing the largest change in luminescence, with a loss of $17.5 \%$. A drop of $12.5 \%$ was observed with the 50 ng sample of 2,4-DNT, and the $5 \mathrm{ng}$ sample gave a change of $4 \%$. The corresponding sensing efficiency seen from the average of three control samples of neat acetonitrile was $1.9 \%$ with a standard error of $0.36 \%$. This degradation can be attributed to photo- and thermal degradation due to the excitation of the laser and the heat from the heating element.

Fig. 6 shows the colour change of the alcoholic potassium hydroxide tests. A clear colour change visible to the naked eye was only seen for DNT masses of $50 \mu \mathrm{g}$ and higher. Testing explosive swabs with organic semiconductor sensors therefore offers a significant advantage over colorimetric spot tests in sensitivity and by removing the interpretation of a colour change. Fig. 5 shows that fluorescence-based methods can easily detect as low as $5 \mathrm{ng}$ of 2,4-DNT drop-cast onto the surface, which is three orders of magnitude lower than the alcoholic potassium hydroxide test which does not show any observable colour change at $5 \mu \mathrm{g}$.

\subsection{Sensor response to swabs from pre- and post-blast IEDs}

All samples gave a positive detection of explosives, although we note that the acetone-wetted Aflas swab collected from the raw TNT materials was damaged in transit and unable to be analysed.

3.2.1 Swabs from bulk explosives. Fig. 7a \& b show the fluorescence detection response to swabs of bulk explosives. The dry Aflas-coated swabs showed a significantly higher response
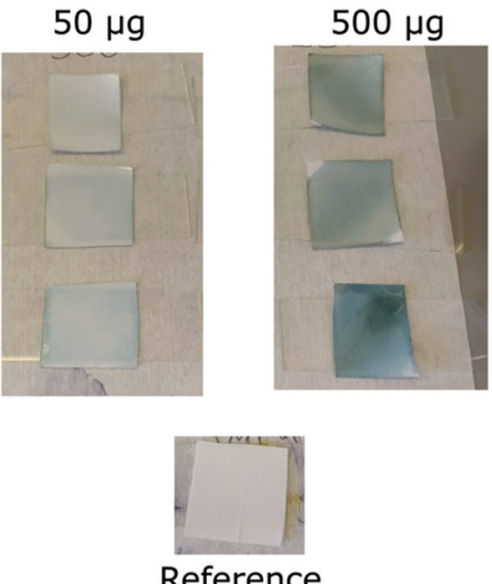

\section{$50 \mathrm{ng}$}

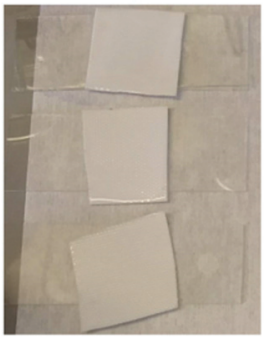

\section{$5000 \mathrm{ng}$}
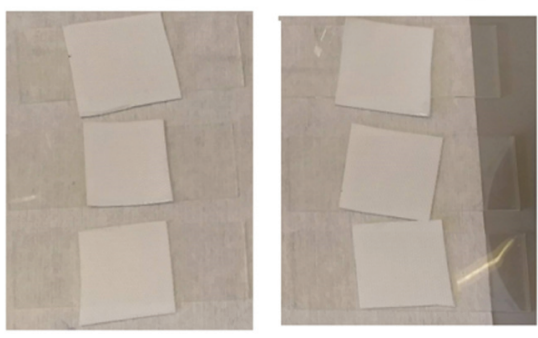

Fig. 6 Response of the potassium hydroxide test to $500 \mu \mathrm{g}-50 \mathrm{ng}$ of 2,4-DNT. The colour changes observed indicate the presence of dinitrotoluene.

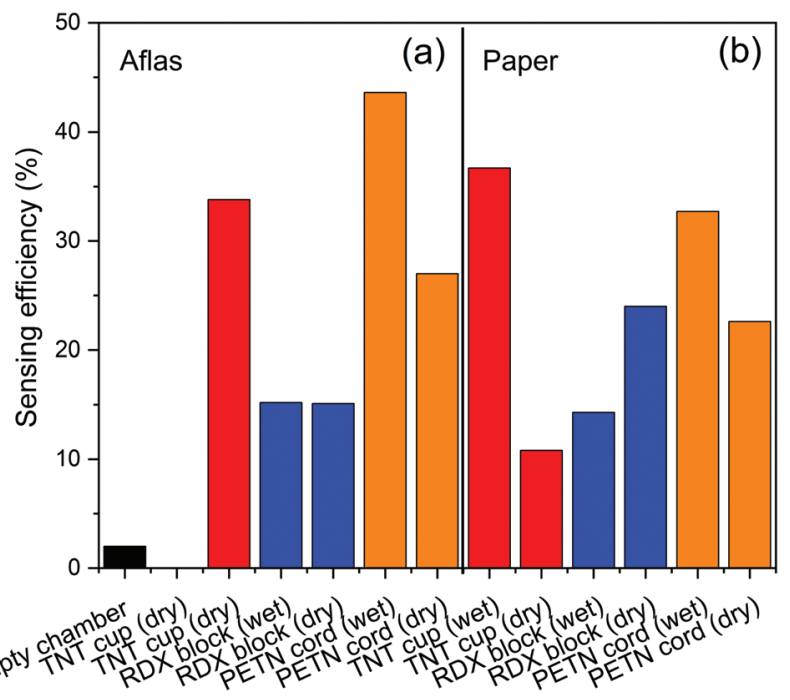

Fig. 7 Sensor responses to blank, Aflas coated (a) and plain paper (b) swabs collected directly from the explosive materials. Black bars are empty chamber control measurements, red bars are TNT, blue bars RDX, and orange bars PETN.

than dry paper swabs for TNT and slightly higher response than dry paper swabs for PETN, while the response to RDX was broadly similar across the four types of swab. Wetted Aflas 
swabs showed a higher response when swabbing for PETN than wet paper swabs. No clear trend is observed for the three explosives sampled when comparing wet $v s$. dry swabs and/or Aflas vs. plain paper however the Aflas-coated filters show a higher overall level of quenching. This is most likely due to the fact that high levels of materials would be picked up from a block of raw explosive compared to trace amounts from contaminated surfaces. This may indicate that Aflas has no significant advantage over plain paper swabs at comparatively high collection (>mg) masses.

3.2.2 Swabs from IED packages. Fig. 8a \& b shows the response of sensors exposed to swabs taken from the IED packages pre-detonation. Both wet and dry Aflas coated swabs showed a higher response for swabs taken from the bag containing PETN over the other IEDs. Plain paper swabs taken from the box containing RDX showed slightly better performance than the equivalent Aflas swabs. Dry Aflas swabs performed significantly better than the dry paper swabs taken from the tote bag containing TNT, with the plain paper swab response comparable to the response of a sensor to an empty sensing chamber, however this trend is reversed for wet swabs of the TNT device.

3.2.3 Swabs from post-blast craters. The response of fluorescence sensors to swabs sampling the blast-craters after detonating the IED packages are shown in Fig. 9a \& b. The wet Aflas swab taken from the blast crater of the TNT device shows much better performance than using dry Aflas and both wet and dry plain paper swabs of the same crater, however the dry Aflas swab had poorer performance than the dry paper swab. Wet plain paper swabs showed better performance than wet Aflas swabs for the RDX and PETN device craters. Dry Aflas

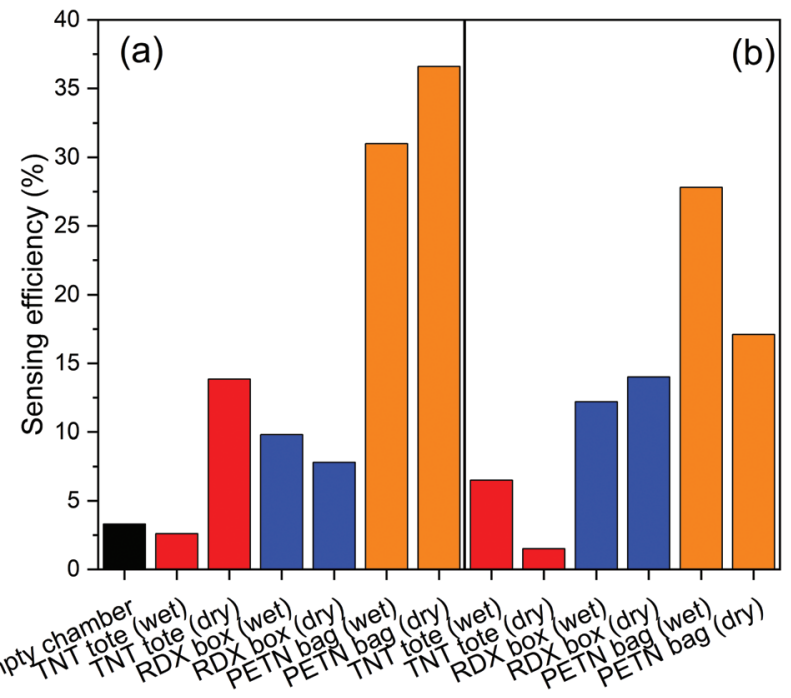

Fig. 8 Response to contaminants swabbed using Aflas coated (a) and plain paper (b) swabs from a canvas tote bag (TNT), a cardboard box (RDX), and a nylon sports bag (PETN). Black bars are empty chamber control measurements, red bars are TNT, blue bars RDX, and orange bars PETN.

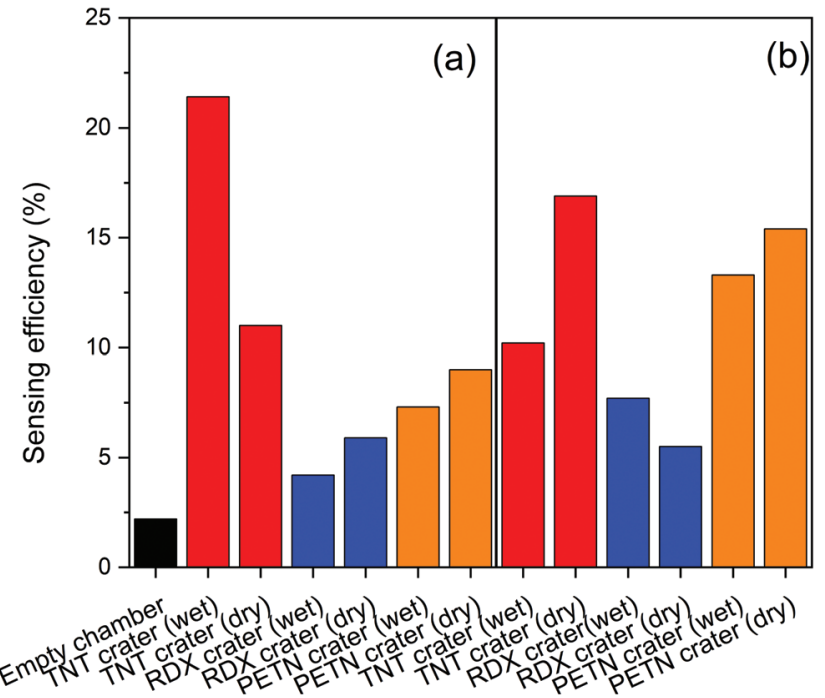

Fig. 9 Sensor responses to an empty chamber, Aflas coated (a) and plain paper (b) swabs collected from the blast crater left behind when the IED-like devices were detonated. Black bars are empty chamber control measurements, red bars are TNT, blue bars RDX, and orange bars PETN.

and plain paper swabs gave a comparable response when swabbing the RDX device blast crater.

\section{Discussion}

Table 1 collates the associated sensing efficiencies of Fig. 7-9.

These results show that quenching of Super Yellow fluorescence is an effective method for detecting explosives adsorbed to swabs. The Super Yellow polymer shows sufficient sensitivity to detect explosives thermally released from samples collected via swabbing. The fluorescence quenching is observed from swabs both with and without an Aflas

Table 1 Sensing efficiencies for all samples

\begin{tabular}{|c|c|c|c|c|}
\hline \multirow{3}{*}{$\begin{array}{l}\text { Explosive } \\
\text { Sample }\end{array}$} & \multicolumn{4}{|c|}{ Sensing efficiency (\%) } \\
\hline & \multicolumn{2}{|l|}{ Dry } & \multicolumn{2}{|l|}{ Wet } \\
\hline & Paper & Aflas + paper & Paper & Aflas + paper \\
\hline \multicolumn{5}{|l|}{ TNT } \\
\hline Package & 1.4 & 14 & 6.5 & 2.6 \\
\hline Post-blast crater & 17 & 11 & 10 & 21 \\
\hline Raw & 11 & 34 & 37 & - \\
\hline \multicolumn{5}{|l|}{ RDX } \\
\hline Package & 14 & 7.8 & 12 & 9.8 \\
\hline Post-blast crater & 5.5 & 5.9 & 7.7 & 4.2 \\
\hline Raw & 24 & 15 & 14 & 15 \\
\hline \multicolumn{5}{|l|}{ PETN } \\
\hline Package & 17 & 37 & 28 & 31 \\
\hline Post-blast crater & 15 & 9 & 13 & 7.3 \\
\hline Raw & 23 & 27 & 33 & 44 \\
\hline
\end{tabular}


coating, and from dry swabs or those wetted with acetone. The higher sensing efficiencies are mostly from swabs taken from the raw explosives and several from IED swabbing, whereas swabs taken of the post-blast crater tend to give lower sensing efficiencies.

The spread of responses may be primarily due to the nonuniform and non-repeatable spread of material mass across the preconcentrators themselves, the surface of the packages, and the amount of material left in a post-detonation crater. Direct contact of pre-detonated material in Fig. 7 and 8 gives a higher quenching response of up to $43 \%$, while post-blast the response is less than half that value. The crater is less likely to have as much raw material since the majority of explosive is expected to be consumed during the detonation. As our vapour characterisation of the Super Yellow films in the current work only allowed binary levels of zero and near-saturated vapour pressure, calibration with quantified amounts of TNT, PETN and RDX that are thermally released is not currently feasible, but in future this would help quantify the levels of explosive in each case. Super Yellow sensors otherwise show very repeatable response, and using the quenching behaviour observed in Fig. 5, the data may be extrapolated to estimate an approximate upper quantity of explosive swabbed at around $1 \mathrm{mg}$.

These results compare well with other swabbing materials and analytical methods. For instance, the LoD in this work is below $5 \mathrm{ng}$, which is significantly more sensitive than the $\mu \mathrm{g}$ LoD found for electrochemical sensors for TNT, ${ }^{33}$ and comparable with microcapillary lab-on-chip devices, ${ }^{34}$ and other fluorescence-based sensors. ${ }^{35}$

In their pristine form, the sensor films are not selective and so may give false positives from chemical compounds similar to explosives, like pesticides or perfume ingredients. However, future work to enhance specificity and selectivity via molecular imprinting of the polymers, ${ }^{36-39}$ and sensor arrays ${ }^{27,40}$ of polymers of differing sensitivity to individual explosives will be investigated. A sensitive, specific sensor for explosives in conjunction with an inexpensive swab will offer a method to "fingerprint" explosives from unknown IED mixtures.

These preliminary results show that a method using preconcentrator swabs in conjunction with conjugated polymer films is a promising approach for initial forensic examination of suspicious packages or post-detonation surfaces.

\section{Conclusions}

The use of a light-emitting organic semiconductor has been shown to be sensitive to explosives swabbed on an inexpensive substrate, with a limit of detection at least three orders of magnitude smaller than current colour-change methods. Detecting explosives with fluorescence quenching has been shown to be applicable to the raw explosive materials, contaminated everyday objects as IED carriers, and post-blast craters. Coating a swab with fluoropolymer Aflas does not give a significant advantage over plain paper swabs at comparatively high $(>\mathrm{mg})$ masses. The results indicate that this is a fast, inexpensive method to detect explosives from a variety of household items typically used in IED packages, and in post-blast environments. The size and cost of these materials, and their relative ease of integration in a portable instrument, point towards a promising method for in-field explosives detection.

\section{Notes}

Data supporting this research can be found at https://doi.org/ 10.17630/995a56e4-d61e-4d27-b192-e73db61c7818.

\section{Conflicts of interest}

There are no conflicts of interest to declare.

\section{Acknowledgements}

The authors acknowledge funding from the EPSRC DTG (EP/ L505079/1) and EPSRC (EP/N509759/1).

\section{References}

1 F. Porritt, M. Shapiro, P. Waggoner, E. Mitchell, T. Thomson, S. Nicklin and A. Kacelnik, Appl. Anim. Behav. Sci., 2015, 166, 112-122.

2 L. P. de Oliveira, D. P. Rocha, W. R. de Araujo, R. A. A. Munoz, T. Paixao and M. O. Salles, Anal. Methods, 2018, 10, 5135-5163.

3 W. R. de Araujo, T. M. G. Cardoso, R. G. da Rocha, M. H. P. Santana, R. A. A. Munoz, E. M. Richter, T. Paixao and W. K. T. Coltro, Anal. Chim. Acta, 2018, 1034, 1-21.

4 A. Raza and B. Saha, Forensic Sci. Int., 2014, 237, e42-e46.

5 N. Cennamo, G. D'Agostino, R. Galatus, L. Bibbo, M. Pesavento and L. Zeni, Sens. Actuators, B, 2013, 188, 221-226.

6 G. Della Giustina, A. Sonato, E. Gazzola, G. Ruffato, S. Brusa and F. Romanato, Mater. Lett., 2016, 162, 44-47.

7 J. L. McDougall and R. J. J. Simkins, The identification of traces of explosives by field spot tests, Report 122, Ministry of Defence Research and Development Establishment, 1973.

8 C. J. Cumming, C. Aker, M. Fisher, M. Fox, M. J. la Grone, D. Reust, M. G. Rockley, T. M. Swager, E. Towers and V. Williams, IEEE Trans. Geosci. Remote Sens., 2001, 39, 1119-1128.

9 S. W. Thomas, III, G. D. Joly and T. M. Swager, Chem. Rev., 2007, 107, 1339-1386.

10 S. Rochat and T. M. Swager, ACS Appl. Mater. Interfaces, 2013, 5, 4488-4502.

11 H. Sohn, M. J. Sailor, D. Magde and W. C. Trogler, J. Am. Chem. Soc., 2003, 125, 3821-3830. 
12 S. J. Toal and W. C. Trogler, J. Mater. Chem., 2006, 16, 2871-2883.

13 R. N. Gillanders, I. D. W. Samuel and G. A. Turnbull, Sens. Actuators, B, 2017, 245, 334-340.

14 N. Bolse, R. Eckstein, M. Schend, A. Habermehl, C. Eschenbaum, G. Hernandez-Sosa and U. Lemmer, Flexible Printed Electron., 2017, 2, 024001.

15 Y. Geng, M. A. Ali, A. J. Clulow, S. Q. Fan, P. L. Burn, I. R. Gentle, P. Meredith and P. E. Shaw, Nat. Commun., 2015, 6, 8240.

16 P. E. Shaw and P. L. Burn, Phys. Chem. Chem. Phys., 2017, 19, 29714-29730.

17 C. Curnrning, M. Fisher and J. Sikes, Amplifying fluorescent polymer arrays for chemical detection of explosives, 2004.

18 D. S. Moore, Rev. Sci. Instrum., 2004, 75, 24992512.

19 R. N. Gillanders, J. M. E. Glackin, J. Filipi, N. Kezic, I. D. W. Samuel and G. A. Turnbull, Sci. Total Environ., 2019, 658, 650-658.

20 P. Wang, N. S. Schneider and N. H. Sung, J. Appl. Polym. Sci., 1999, 71, 1525-1535.

21 R. A. McGill, M. H. Abraham and J. W. Grate, Chemtech, 1994, 24, 27-37.

22 J. W. Grate, R. Ozanich, J. S. Hartman, M. J. O'Hara and O. B. Egorov and Ieee, in 2007 Ieee Sensors, Vols 1-3, 2007, pp. 1357-1360, DOI: 10.1109/icsens.2007.4388663.

23 K. Cizek, C. Prior, C. Thammakhet, M. Galik, K. Linker, R. Tsui, A. Cagan, J. Wake, J. La Belle and J. Wang, Anal. Chim. Acta, 2010, 661, 117-121.

24 S. V. F. Castro, R. M. Cardoso, M. H. P. Santana, E. M. Richter and R. A. A. Munoz, Talanta, 2019, 203, 106-111.

25 R. M. Cardoso, S. V. F. Castro, M. N. T. Silva, A. P. Lima, M. H. P. Santana, E. Nossol, R. A. B. Silva, E. M. Richter, T. Paixao and R. A. A. Munoz, Sens. Actuators, B, 2019, 292, 308-313.

26 R. C. Sharma, S. Kumar, S. Gautam, S. Gupta and H. B. Srivastava, Sens. Actuators, B, 2017, 243, 59-63.
27 R. N. Gillanders, I. A. Campbell, F. Chen, P. Morawska, I. D. W. Samuel and G. A. Turnbull, 4th International Conference on Photonics, Optics and Laser Technology (PHOTOPTICS), 2016, pp. 1-5.

28 R. N. Gillanders, I. A. Campbell, J. M. E. Glackin, I. D. W. Samuel and G. A. Turnbull, Talanta, 2018, 179, 426-429.

29 R. G. Ewing, M. J. Waltman, D. A. Atkinson, J. W. Grate and P. J. Hotchkiss, TrAC, Trends Anal. Chem., 2013, 42, 35-48.

30 C. A. Taylor and W. H. Rinkenbach, J. Am. Chem. Soc., 1923, 45, 44-59.

31 M. E. Sitzmann and S. C. Foti, J. Chem. Eng. Data, 1975, 20, 53-55.

32 R. N. Roberts and R. H. Dinegar, J. Phys. Chem., 1958, 62, 1009-1011.

33 P. Ryan, D. Zabetakis, D. A. Stenger and S. Trammell, Sensors, 2015, 15, 17048-17056.

34 M. Ueland, L. Blanes, R. V. Taudte, B. H. Stuart, N. Cole, P. Willis, C. Roux and P. Doble, J. Chromatogr. A, 2016, 1436, 28-33.

35 S. J. Toal, J. C. Sanchez, R. E. Dugan and W. C. Trogler, J. Forensic Sci., 2007, 52, 79-83.

36 S. S. Cao, J. R. Chen, W. C. Sheng, W. W. Wu, Z. Y. Zhao and F. Long, Molecularly Imprinted Sensors: Overview and Applications, 2012, pp. 57-72, DOI: 10.1016/b978-0-44456331-6.00003-7.

37 Y. Kim, J. B. Jeon and J. Y. Chang, Mater. Lett., 2016, 182, 235-239.

38 S. Lordel, F. Chapuis-Hugon, V. Eudes and V. Pichon, Anal. Bioanal. Chem., 2011, 399, 449-458.

39 X. Y. Wang, J. L. Yu, X. Q. Wu, J. Q. Fu, Q. Kang, D. Z. Shen, J. H. Li and L. X. Chen, Biosens. Bioelectron., 2016, 81, 438444.

40 N. Bolse, R. Eckstein, M. Schend, A. Habermehl, G. Hernandez-Sosa, C. Eschenbaum and U. Lemmer, Proc. SPIE 10231, Optical Sensors 2017, 102310R (16 May 2017), DOI: $10.1117 / 12.2265522$. 